\title{
The influence of surface kinetics in modelling chemical vapour deposition processes in porous preforms
}

\author{
J. P. DEKKER ${ }^{\dagger}$, R. MOENE*, J. SCHOONMAN \\ Laboratory for Applied Inorganic Chemistry, and *Department of Chemical Process \\ Technology, Delft University of Technology, Julianalaan 136, 2628 BL Delft, The Netherlands
}

The isothermal chemical vapour infiltration (ICVI) process is a well known technique for the production of composites and the surface modification of porous preforms. Mathematical modelling of the process can provide a better understanding of the influence of individual process parameters on the deposition characteristics such as final porosity or deposition profiles in the pore network. The influence of different rate expressions for several binary compounds on the ICVI process is discussed. Experimental work is used to validate the importance of correct kinetic expressions in a continuous ICVI model for cylindrical pores. The predicted infiltration characteristics are compared with experimental results. The final densification and Thiele modulus, i.e. a number which is a measure for the diffusion limitations in a pore, are used for the evaluation of the presented model, and conditions are given for an optimal densification of a porous preform by the ICVI process for several binary compounds. The deposition profiles as predicted by the model calculations are in agreement with the experimentally determined deposition profiles of TiN and TiC in small tubes.

Moreover, it can be concluded that the shape of the deposition profiles is determined by the heterogeneous reaction kinetics. There is only a qualitative agreement between the predicted densification and measured densification for the synthesis of $\mathrm{TiN}$ and $\mathrm{TiB}_{2}$ in sintered porous alumina. This mismatch can be explained in terms of a complexity of the pore network and differences in reaction kinetics. Model calculations reveal that there is a scattering for the predicted residual porosity as a function of the Thiele modulus for TiN. Moreover, this Thiele modulus can not fully account for the changes in densification at different temperatures. Given these uncertainties it is likely that a residual porosity of less than one percent can be obtained if the Thiele modulus is smaller than $1 \times 10^{-4}$. However, a CVI process with such a small Thiele modulus will not be practical, because of the concomitant long process times. Therefore, more precise conditions for the individual process parameters, i.e. concentration, reactor pressure, and temperature are deduced from the model calculations.

\section{Nomenclature}

$a, b, c$ reaction order constants

$C_{\mathrm{i}}(x, t) \quad$ concentration of species $i$ at axial position $x$ and time $t\left(\right.$ mole $\left.^{-3}\right)$

$C_{\mathrm{i}}^{0} \quad$ bulk concentration of species $i\left(\right.$ mole $\left.^{-3}\right)$

$C_{i}^{*}(x, t)$ dimensionless concentration of species $i$ at axial position $x$ and time $t$

$D_{\mathrm{e}}(x, t)$ effective diffusion coefficient at axial position $x$ and time $t\left(\mathrm{~m}^{2} \mathrm{~s}^{-1}\right)$

$D_{\mathrm{ij}}(x, t)$ binary diffusion coefficient $\left(\mathrm{m}^{2} \mathrm{~s}^{-1}\right)$

$D_{\mathrm{K}}(x, t)$ Knudsen diffusion coefficient at position $x$ and time $t\left(\mathrm{~m}^{2} \mathrm{~s}^{-1}\right)$

$F \quad$ correction factor for effective diffusion coefficient $k \quad$ growth rate constant $\left(\mathrm{ms}^{-1}\left(\mathrm{~m}^{3} \text { mole }{ }^{-1}\right)^{\mathrm{a}+\mathrm{b}-1}\right)$

$K_{\mathrm{i}}$ adsorption-desorption equilibrium constant $\left(\mathrm{m}^{3}\right.$ mole $\left.^{-1}\right)$

$L \quad$ length of a pore (m)

$M_{\mathrm{i}} \quad$ molecular weight of species $i\left(\mathrm{~g} \mathrm{~mole}^{-1}\right)$

$M_{\mathrm{ij}} \quad$ harmonic mean of the molecular weights of species $i$ and $j\left(\mathrm{~g} \mathrm{~mole}^{-1}\right.$ )

$M_{\mathrm{s}} \quad$ molecular weight of deposit $\left(\mathrm{g} \mathrm{mole}^{-1}\right)$

$m_{1} \quad$ measured mass increase $(\mathrm{g})$

$n_{\mathrm{i}} \quad$ stoichiometric number

$P \quad$ reactor pressure $(\mathrm{Pa})$

$R\left(C_{\mathrm{i}}\right) \quad$ growth rate (mole $\left(\mathrm{m}^{-2} \mathrm{~s}^{-1}\right)$ )

$r(x, t) \quad$ pore radius at position $x$ and time $t(\mathrm{~m})$

${ }^{\dagger}$ Current address: Philips OFT, P.O. Box 218, 5600 MD Eindhoven, The Netherlands. 


\begin{tabular}{|c|c|}
\hline$r^{0}$ & initial pore radius (m) \\
\hline$r^{*}$ & dimensionless pore radius \\
\hline$S$ & geometrical surface area $\left(\mathrm{m}^{2}\right)$ \\
\hline$s^{1}$ & $\begin{array}{l}\text { fraction of free titanium sites at the surface } \\
\text { of TiN }\end{array}$ \\
\hline$s^{n}$ & $\begin{array}{l}\text { fraction of free nitrogen sites at the surface } \\
\text { of TiN }\end{array}$ \\
\hline$T$ & temperature $(\mathrm{K})$ \\
\hline$t$ & time $(s)$ \\
\hline$t_{\mathrm{p}}$ & process time (s) \\
\hline$U$ & $K_{\mathrm{HCl}} /\left(K_{\mathrm{H}_{2}} C_{\mathrm{H}_{2}}\right)^{1 / 2}\left(\mathrm{~m}^{3} \mathrm{~mole}^{-1}\right)$ \\
\hline$V$ & volume of alumina substrate $\left(\mathrm{m}^{3}\right)$ \\
\hline$W$ & $K_{\mathrm{TiCl}_{3}\left(\mathrm{~m}^{3} \mathrm{~mole}^{-1}\right)}$ \\
\hline$X$ & $\begin{array}{l}\text { volume of infiltrated deposit relative to in- } \\
\text { itial pore volume }\end{array}$ \\
\hline$x$ & axial distance $(\mathrm{m})$ \\
\hline$x^{*}$ & dimensionless axial distance \\
\hline$z$ & number of time steps \\
\hline$\alpha$ & dummy variable for integration \\
\hline$\varepsilon$ & $\begin{array}{l}\text { porosity of sintered porous alumina sub- } \\
\text { strate }\end{array}$ \\
\hline$\lambda$ & $\begin{array}{l}\text { ratio of the volume over the surface area } \\
\text { perpendicular to the flux (m) }\end{array}$ \\
\hline$\rho$ & density deposit $\left(\mathrm{kg} \mathrm{m}^{-3}\right)$ \\
\hline$\sigma_{i j}$ & a characteristic length $(A)$ \\
\hline$\tau$ & tortuosity factor of substrate \\
\hline$\varphi$ & Thiele modulus \\
\hline$\Omega_{\mathrm{D}}$ & collision integral \\
\hline
\end{tabular}

\section{Introduction}

Hot-wall chemical vapour deposition (CVD) has become a well-known technique for the synthesis of thin ceramic layers on dense substrates [1]. These ceramic layers are used because of their good wear resistance and chemical stability under severe conditions. In the last decade there has been an increasing interest in the modification of porous performs by the hot-wall CVD process [2-15]. This type of isothermal CVD process is known as the isothermal chemical vapour infiltration (ICVI) process. The CVI process can be divided into two classes depending on process conditions and its application, i.e. CVI processes using long process times of up to $500 \mathrm{~h}$ for the synthesis of dense composites, and CVI processes using relatively short process times of less than $10 \mathrm{~h}$ for the surface modification of porous systems.

A well known CVI process using long process times is the densification of porous fibre preforms to produce ceramic composites with a high toughness and strength [7-12]. In general, these long process times are necessary for a full densification of the porous preform. Different reactor geometries are developed to improve the densification. For example, a forced flow through the porous preform will result in shorter process times due to higher deposition rates, and a temperature gradient opposite to the reactant flux in the porous preform will result in a higher final density. A combination of these two modifications has resulted in the development of the ORNL (Oak Ridge National Laboratory) CVI process [16-18]. These modifications on the CVI process can reduce the process time considerably. The principle of a better densification using a temperature gradient opposite the mass transfer flux in a porous preform has been discussed in a paper on the mathematical modelling of the CVI process using volume heating [19]. This volume heating (from the inside to the outside) can be induced by inductive or microwave heating of the preform.

The CVI process using relatively short process times can be used to modify the internal surface of a porous preform with only a thin deposit. For example, a bundle of fibres can be coated with a thin layer for the protection of the individual fibres, and each fibre should be coated with a thin chemically inert deposit without interconnecting the fibres in the bundle [20]. Furthermore, the CVI process using short process times can be used to deposit a thin layer in a porous preform for the modification of ceramic membranes [21], or for the improvement of the mechanical strength of sintered porous metals [22] and ceramics [23]. This CVI technique using relatively short process times is promising as a novel synthesis method for catalyst materials [24].

Mathematical modelling of the process can give a better understanding of the influence of individual process parameters on the deposition characteristics such as final porosity or deposition profiles in the pore network. The change in pore geometry due to the formation of a solid in the pores, and as a result the change in diffusion rate of the reactants in the pores during the process, should be described by the model, and correct kinetic equations taken from literature [25-36] should be implemented in the model, because the extent of depletion of the diffusing reactants in the pore network is determined by a combination of diffusion and reaction kinetics.

The importance of reaction kinetics in the CVI process has been recognized by Middleman [37], and Sheldon [38]. They have reported theoretical considerations concerning the optimization of the densification process by tailoring the chemistry. They have discussed the influence of a possible gas phase reaction, which supplies the intermediate species for the heterogeneous reaction in the CVI process. According to their discussion concerning the homogeneous and heterogeneous reaction rate relative to the diffusion rate, it is concluded that a slow homogeneous reaction can improve the densification. However, they have not considered the influence of the changing pore geometry during the process on the final porosity, and they have not validated their model with experimental results.

Usually, a simple first order reaction rate dependence with respect to the gas phase concentration is assumed to be present. However, it is obvious that this assumption is often not correct. For example, the reaction rate of many binary compounds is not first order with respect to their reactant gas phase concentrations. Often, these reaction kinetics can be described by an adsorption-reaction mechanism based on an isothermal Langmuir adsorption behaviour. Kinetics based on an adsorption-reaction mechanism has been found for several CVD reactions, e.g. titanium nitride (TiN) [25-27], titanium carbide (TiC) [28], titanium diboride $\left(\mathrm{TiB}_{2}\right) \quad[29,30]$, boron 
phosphide (BP) [31], boron carbide $\left(\mathrm{B}_{\mathrm{x}} \mathrm{C}_{\mathrm{y}}\right.$, $\mathrm{x} / \mathrm{y} \in[4,9])[32]$, silicon nitride $\left(\mathrm{Si}_{3} \mathrm{~N}_{4}\right)[33,34]$, and silicon carbide $(\mathrm{SiC})[35,36]$. The influence of these different adsorption-reaction mechanisms on the CVI densification will be discussed. In this paper, it will be shown that the generally accepted conditions for an optimal densification, i.e. low pressure and reaction temperature $[6,15,39,40]$, are only valid for an ICVI process where the growth rate exhibits a first order dependence in the reactant gas phase concentration. Furthermore, the predicted model results are validated using experimental CVI data for several binary compounds. The implications of a complex reaction mechanism on the Thiele modulus, i.e. a number which is a measure for the diffusion limitations in a pore, will be discussed, and this Thiele modulus is used for the evaluation of the densification as a function of the process parameters.

\section{Review of mathematical models}

The analytical modelling of diffusion and deposition in small tubes has been reported by Van den Brekel et al. [41]. They presented an analytical solution for a mass balance in which the diffusion of a species in a tube in the axial direction and a first order heterogenous reaction at the inside of the tube is incorporated. Tai and Chou $[42,43]$ presented an analytical solution for the isothermal and isobaric CVI process for the densification of porous fibre preforms in which the diffusion in the radial direction is considered as well. The analytical solution for the mass balance presented by Van den Brekel et al. [41] was used by Rossignol et al. [15] to evaluate their experimental results on the ICVI of $\mathrm{TiC}$ in a fibre preform. However, the predicted process time for a given densification was an order shorter than the observed process time. This is a consequence of the fact that they have not included the variation of the pore cross-sectional area in the model. Naslain et al. [40] did take the decrease in diffusivity into account by introducing an incremental calculation in time for the analytical solution of the mass balance for the ICVI process as proposed by Rossignol et al. [15]. However, this approach is only justified if the decrease in deposition thickness as a function of axial distance is negligible. Moene et al. [39], Gupte and Tsamopoulos [44], Lin $[21,45]$, and Fedou et al. [46] have presented a continuous model for the densification of a cylindrical pore where the change in pore geometry has been taken into account. The results on the experimental validation of such a model for a first order reaction was in reasonable agreement [46]. Any mismatch between experiment and mathematica! model is explained in terms of a non-realistic kinetic expression which was implemented in the models $[44,46]$. Hitherto, all models used the concept of straight cylindrical pores and any deviation in such an idealized pore geometry was only corrected for the mass transfer by introducing a tortuosity factor. There is an increasing number of reports on the modelling of mass transfer in more complex porous networks taking into account pressure and temperature gradients [47-56].
However, all these models consider only first order reaction kinetics.

\section{The mathematical model}

A mathematical description of a CVD process in an open cylinder of length $L$ and radius $r$ under isothermal and isobaric conditions is used to evaluate the influence of the kinetic expressions for several binary compounds on the infiltration characteristics. The description of the mass balance for the mass transport in a cylinder is complicated because of the changing pore geometry due to the formation of a solid at the inside of the cylinder. Therefore, some assumptions have been made which are common for the modelling of a CVI process $[21,44,46,52]$.

It is assumed that the diffusion is one dimensional. This implies that there is no concentration gradient in the radial direction of the cylinder. This is valid as long as the length over radius ratio is large. Surface diffusion is assumed to be small with respect to the mass transfer in the gas phase. Normal Fick diffusion is applied which is valid as long as the concentration of the diffusing species is small. Consequently, any pressure gradient due to a heterogeneous reaction can be neglected. Furthermore, a pseudo-steady state approximation is made. This is justified provided that the density of the solid deposit is large with respect to the gas phase [57]. Now, the mass balance of a diffusing species over a differential volume $\pi r^{2} . \mathrm{d} x$ in a cylinder as depicted in Fig. 1 can be written as,

$$
\frac{\mathrm{d}^{2} C_{\mathrm{i}}(x, t)}{\mathrm{d} x^{2}}=\frac{2 n_{\mathrm{i}} R\left(C_{\mathrm{i}}\right)}{r(x, t) D_{\mathrm{e}}(x, t)}
$$

where $C_{\mathrm{i}}(x, t)$ is the concentration of species $i, r(x, t)$ the pore radius, $D_{\mathrm{e}}(x, t)$ the effective diffusion coefficient at position $x$ and time $t$, and $R\left(C_{1}\right)$ the heterogeneous reaction rate per unit surface area. This mass balance describes the mass transport of a reactant species $i$ if $n_{\mathrm{i}}$ is a positive integer equal to the number of reactant species $i$ necessary for the production of the

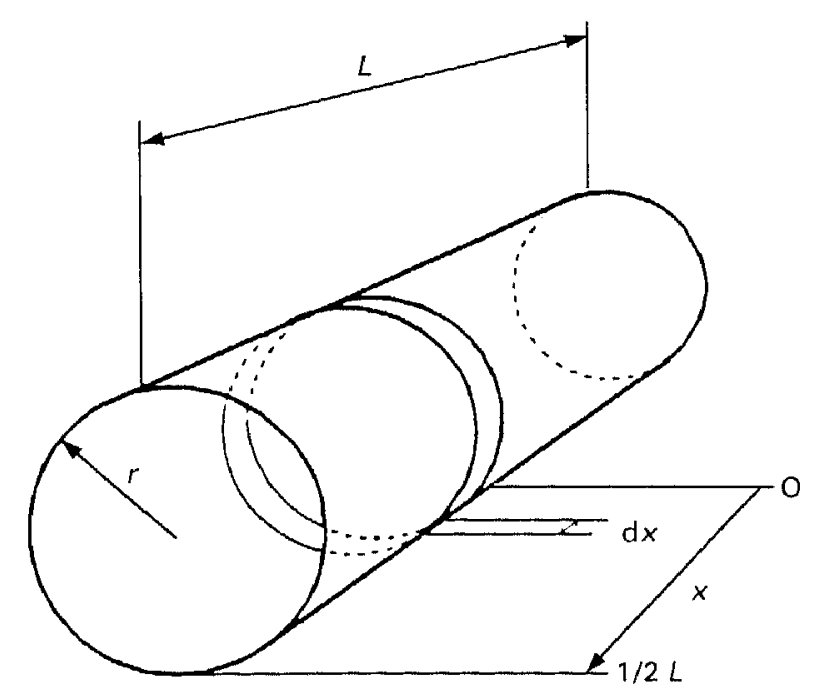

Figure I Schematic drawing of the pore geometry used in the ICVI model. 
deposit normalized to the number of solid species formed. Alternately this mass balance describes the mass transport of a gaseous byproduct if $n_{\mathrm{i}}$ is a negative integer equal to the number of gaseous byproduct species $i$ produced relative to the number of solids formed. The mass balance for the deposition of a solid on the cylinder wall is,

$$
\frac{\mathrm{d} r(x, t)}{\mathrm{d} t}=-\frac{M_{\mathrm{s}} R\left(C_{\mathrm{i}}\right)}{\rho}
$$

where $M_{\mathrm{s}}$ is the molecular weight, and $\rho$ the density of the deposited material. The boundary conditions for the mass balances are given by,

$$
\begin{gathered}
\frac{\mathrm{d} C_{\mathrm{i}}(0, t)}{\mathrm{d} x}=0 \\
C_{\mathrm{i}}\left(\frac{L}{2}, t\right)=C_{\mathrm{i}}^{0} \\
r(x, 0)=r^{0}
\end{gathered}
$$

where $C_{i}^{0}$ is the bulk concentration of species $i$, and $r^{0}$ is the initial pore radius. Now, this set of equations can be solved provided that the diffusion coefficient and reaction rate are known.

Diffusion: The mass transfer of a species in the pores is determined by molecular diffusion or Knudsen diffusion depending on the pore radius and mean free path of the molecules in the gas phase. The effective diffusion coefficient can be approximated by assuming it to be equal to the harmonic mean of the molecular diffusion coefficient and the Knudsen diffusion coefficient according to Equation (6)

$$
\frac{1}{D_{\mathrm{e}}(x, t)}=F\left(\frac{1}{D_{\mathrm{ij}}}+\frac{1}{D_{\mathrm{K}}(x, t)}\right)
$$

where $D_{\mathrm{ij}}$ is the binary diffusion coefficient in the gas phase, $D_{\mathrm{K}}(x, t)$ the Knudsen diffusion coefficient at position $x$ and time $t$ in the pore, and $F$ a correction factor for the complexity of the pore network, i.e. in this case equal to the tortuosity factor $(\tau)$. A binary diffusion coefficient can be determined from the semiempirical relation as proposed by Wilke and Lee [58]

$$
D_{i j}=\frac{\left(2.14 M_{i j}^{1 / 2}-0.49\right)}{M_{i j}} \frac{10^{-2} T^{3 / 2}}{P \sigma_{i j}^{2} \Omega_{D}}
$$

where $\sigma_{\mathrm{ij}}$ is a characteristic length of species $A$ and $B$, and $\Omega_{\mathrm{D}}$ the collision integral of the Lennard-Jones potential, $M_{\mathrm{ij}}$ the harmonic mean of the molecular weights of the species $i$ and $j, P$ the pressure, and $T$ the temperature. The values $\sigma_{i j}, \Omega_{D}$ are tabulated or can be approximated $[58,59]$. This relation is based on the theoretical Chapman-Enskog relation for a binary diffusion coefficient. A discussion on the calculation of binary diffusion coefficients at relatively low pressures is given by Reid et al. [58]. The Knudsen diffusion coefficient can be determined from the relation for diffusion in a straight cylindrical pore of infinite length [59]

$$
D_{\mathrm{K}}=97 r(x, t)\left(\frac{T}{M_{\mathrm{i}}}\right)^{1 / 2}
$$

where $M_{\mathrm{i}}$ is the molecular weight of the diffusing species $i$. The effective diffusion coefficients for species $i$ are calculated in order to solve the mass balances for the reactants in the pore. It is assumed that the diffusion coefficient of a species $i$ with a low concentration is independent of the presence of other diffusing species with a low concentration.

Reaction rate: The reaction rate for binary compounds can often be described by an adsorption-reaction mechanism based on an isothermal Langmuir adsorption behaviour. The reaction rate expressions taken from reports on CVD kinetics for several binary compounds are listed in Table 1.

The concentrations in the reaction rate expressions in Table I for the synthesis of $\mathrm{TiN}, \mathrm{TiC}, \mathrm{TiB}_{2}$, and $B_{x} C_{y}$ are the homogeneous gas phase equilibrium concentrations in the reactor, and not necessarily the input concentrations. These growth rate expressions describe a reaction mechanism which is determined by a competitive adsorption of several species and a subsequent reaction at the surface. The growth rate can exhibit a zero or negative order with respect to the gas phase concentration. It is assumed that the growth rate mechanisms responsible for the CVD growth rate characteristics are also valid for the CVI processes. Mathematical model calculations have been performed for the synthesis of $\mathrm{TiN}, \mathrm{TiC}$, and $\mathrm{TiB}_{2}$. The experimental data on the formation of $\mathrm{TiN}$ and $\mathrm{TiC}$ in small tubes as reported by Van den Brekel et al. [41] along with our own experimental data on the formation of $\mathrm{TiN}$ and $\mathrm{TiB}_{2}$ in sintered porous alumina are used to validate the importance of the implementation of correct reaction rate equations in the model.

\subsection{Thiele modulus}

The use of the Thiele modulus, i.e. a dimensionless number which is proportional to the square root of the ratio of the heterogeneous reaction over the diffusion rate in a pore is generally accepted as a tool for the evaluation of the modelling of ICVI processes $[7,37-39,45,46,53]$. However, such a number cannot be used to predict the influence of the changing pore geometry during the densification. Furthermore, it is difficult or even impossible to derive a Thiele modulus when the reaction rate has a complex dependence on more than one reactant. Thus, the Thiele modulus can only be determined analytically for ICVI processes at the early stages of the densification process. A generalized form for a Thiele modulus can be derived from Equation $1[60,61]$

$$
\varphi=\lambda R\left(C_{\mathrm{i}}^{0}\right)\left(4 r D_{\mathrm{e}} \int_{0}^{C_{\mathrm{i}}^{0}} R(\alpha) \mathrm{d} \alpha\right)^{-\frac{1}{2}}
$$

where $\varphi$ is the Thiele modulus, $\lambda$ is the ratio of volume over surface area perpendicular to the molecular flux, and $\alpha$ is a dummy variable for integration. This Thiele modulus is based on the principle that in the case of its asymptotic solution the concentration of the reactant deep in the pore has to be zero if the pore is of infinite length or the reaction rate is large with respect to the diffusion rate $[60,61]$. This Thiele modulus can be 
TABLE I Reaction rate expressions for several binary compounds

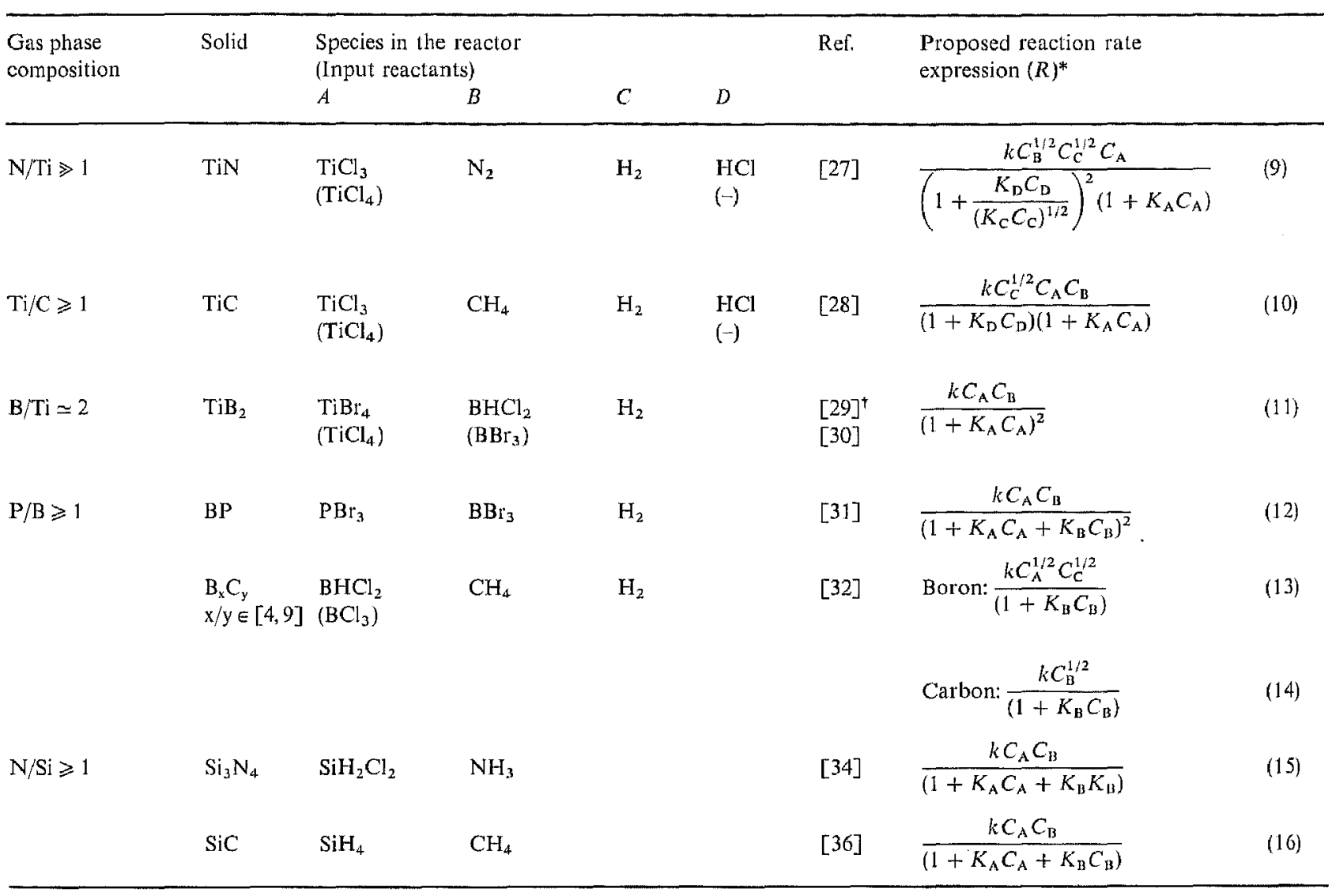

*: $K_{i}$ is the equilibrium adsorption constant for species $i$, and $k$ is the growth rate constant.

$t_{\text {: }}$ Estimated from literature data on the synthesis of $\mathrm{TiB}_{2}$ using $\mathrm{BCl}_{3}$ and $\mathrm{BBr}_{3}$.

solved for any arbitrary kinetic expression provided it has a zero reaction rate at an infinitely small reactant concentration. This condition limits the use of this generalized form of the Thiele modulus if the reaction rate is dependent on more than one reactant species. In this case, a Thiele modulus can be derived only for a species $A$ if all other species $i$ are in large excess in the pore with respect to species $A[62]$, hence, the use of the presented Thiele modulus is only justified if the following condition is valid throughout the pore.

$$
\frac{\mathrm{d}\left(\frac{C_{A}(x)}{C_{\mathrm{i}}(x)}\right)}{\mathrm{d} x} \approx \frac{\mathrm{d} C_{A}(x)}{\mathrm{d} x}
$$

If the growth rate characteristic in the pore is determined by two different species, which are depleted considerably, then the amount of deposited material at a given axial position is determined by the reaction rate expression and the diffusivity of both species. However, only one of these two species can be zero at infinite pore length. This implies that the generalized Thiele modulus cannot account for the influence of the diffusivity of both species on the infiltration kinetics.

\section{Experimental aspects}

\subsection{CVI experimental procedure}

CVI experiments on TiN and $\mathrm{TiB}_{2}$ in tubular sintered porous alumina substrates have been used to evaluate the densification. A hot-wall CVD reactor is used for these experiments. The apparatus for these CVI experiments consists of a quartz tube with a diameter of $49 \mathrm{~mm}$ and a conventional gas handling system. This apparatus was also used for the investigation of the CVD reaction kinetics of $\mathrm{TiN}$ and $\mathrm{TiB}_{2}[27,30]$. The experimental standard conditions are summarized in Table II.

\subsection{Numerical solutions}

The variables in the presented differential equations can be made dimensionless,

$$
\begin{aligned}
x^{*} & =\frac{2 x}{L} \\
r^{*}\left(x^{*}, t^{*}\right) & =\frac{r\left(x^{*}, t\right)}{r^{0}} \\
C^{*}\left(x^{*}, t\right) & =\frac{C\left(x^{*}, t\right)}{C_{\mathrm{j}}^{0}}
\end{aligned}
$$

Now, the mass balance for the transport in the pore can be written as Equation 22,

$$
\frac{\mathrm{d}^{2} C_{\mathrm{i}}^{*}\left(x^{*}, t\right)}{\mathrm{d}\left(x^{*}\right)^{2}}=\frac{8 L^{2} n_{\mathrm{i}}}{r^{0} C_{\mathrm{i}}^{0}} \frac{R\left(C_{\mathrm{i}}^{*}, C_{\mathrm{i}}^{0}\right)}{r^{*}\left(x^{*}, t\right) D_{\mathrm{c}}\left(x^{*}, t\right)}
$$

The solution of the differential equation for the growth rate can be obtained by applying a first-order 
TA B LE II Experimental standard conditions for the synthesis of $\mathrm{TiN}$ and $\mathrm{TiB}_{2}$ in tubular porous alumina substrates

\begin{tabular}{|c|c|c|c|c|}
\hline Parameters & TiN & $\mathrm{TiB}_{2}$ & Substrate & \\
\hline$C_{\mathrm{riCl}_{4}}(\mathrm{STP})$ & $0.2-1.8$ mole m$^{-3}$ & 0.134 mole m$^{-3}$ & Length & $15 \mathrm{~mm}$ \\
\hline$C_{\mathrm{BRr}_{3}}$ (STP) & - & 0.267 mole m$^{-3}$ & Outer & $15 \mathrm{~mm}$ \\
\hline$C_{\mathrm{N}_{2}}(\mathrm{STP})$ & $21-22$ mole $^{-3}$ & & diameter & \\
\hline $\mathrm{C}_{\mathrm{H}_{2}}(\mathrm{STP})$ & $21-22$ mole $^{-3}$ & 22.1 mole m$^{-3}$ & Inner & $9 \mathrm{~mm}$ \\
\hline$C_{\mathrm{Ar}}(\mathrm{STP})$ & - & $22.1 \mathrm{molem}^{-3}$ & diameter & \\
\hline Flow (STP) & $0.6-0.8 \mathrm{~mole} \mathrm{~m}^{-2} \mathrm{~s}^{-1}$ & $0.6-0.8$ mole m$^{-2} \mathrm{~s}^{-1}$ & $r$ (average)* & $2.3 \mu \mathrm{m}$ \\
\hline$P$ & $1 \times 10^{5} \mathrm{~Pa}$ & $0.1-110^{5} \mathrm{~Pa}$ & porosity* & $38.5 \%$ \\
\hline$T$ & $1000-1273 \mathrm{~K}$ & $823-1073 \mathrm{~K}$ & $\tau^{\dagger}$ & 4 \\
\hline$t$ & $3.6-21.6$ & $3.6-28.810^{3} \mathrm{~s}$ & & \\
\hline
\end{tabular}

*: derived from Hg-porosimetry.

t: i.e. the tortuosity factor.

Euler approximation

$$
r^{*}\left(x^{*},\left(t+\frac{t_{\mathrm{p}}}{z}\right)\right)=r^{*}\left(x^{*}, t\right)-\frac{M_{\mathrm{s}} R}{r^{0} \mathrm{\rho}} \frac{t_{\mathrm{p}}}{z}
$$

where $t_{\mathrm{p}}$ is the process time and $z$ the number of time steps. For the numerical solution of these equations the number of slabs in the axial direction, and the number of time steps was increased until the absolute change in the integral for the deposit over the axial distance was less than 0.1 per cent with a doubling of the number of steps in the axial direction and the number of time steps. The input in the model of the geometrical data along with the physical properties of the gas phase is straightforward. However, the input of quantitative values for the constants in the growth rate expressions is difficult, because quantitative data on the kinetics are scarce. Therefore, some assumptions have to be made for each specific chemical system. Model predictions have been made for the synthesis of $\mathrm{TiN}, \mathrm{TiC}$, and $\mathrm{TiB}_{2}$. The assumptions, which have to be made with respect to the chemistry of the process, will be discussed for each chemical system separately.

\subsubsection{Titanium nitride}

Titanium nitride can be formed by $\mathrm{CVD}$ using $\mathrm{TiCl}_{4}$, $\mathrm{N}_{2}$, and $\mathrm{H}_{2}$. In general, $\mathrm{N}_{2}$ and $\mathrm{H}_{2}$ are present in large excess with respect to $\mathrm{TiCl}_{4}$ [25-27]. Therefore, it is assumed that the $\mathrm{N}_{2}$ and $\mathrm{H}_{2}$ concentrations are independent of axial position and time. The growth rate at a given axial position is a function of the homogeneous thermodynamic equilibrium concentration of $\mathrm{TiCl}_{3}$ and $\mathrm{HCl}$ [27]. Thus, the differential equation for the diffusion of $\mathrm{HCl}$ and $\mathrm{TiCl}_{3}$ has to be solved. In addition, the equilibrim between $\mathrm{TiCl}_{4}$ and $\mathrm{TiCl}_{3}$ has to be recalculated each time before Equation 23 is solved. The kinetic parameters of the growth rate expression in Table I can be derived from CVD literature data [25-27].

\subsubsection{Titanium carbide}

Titanium carbide can be formed using $\mathrm{TiCl}_{4}, \mathrm{CH}_{4}$, and $\mathrm{H}_{2}$ [29]. The concentration profiles of the $\mathrm{TiCl}_{3}$ and $\mathrm{CH}_{4}$ species in the pore have to be determined in order to study the ICVI process of TiC. The depletion of hydrogen is neglected because of its large excess. It is assumed that the concentration of $\mathrm{HCl}$ is determined by the gas phase equilibrium between $\mathrm{TiCl}_{4}$ and $\mathrm{TiCl}_{3}$. Furthermore, it is assumed that the surface coverage of adsorbed $\mathrm{HCl}$ on $\mathrm{TiC}$ is of the same order of magnitude as adsorbed $\mathrm{TiCl}_{3}$ on TiC. An estimate for the growth rate constant of the growth rate expression in Table I has been made from the growth rate data as reported by Stjernberg $e t$ al. [28] and Van den Brekel et al. [41]. To our knowledge, there are no data available on the adsorption constants for chloride species on TiC. Therefore, it is assumed that these adsorption constants are equal to the adsorption constants for $\mathrm{TiCl}_{3}$ and $\mathrm{HCl}$ on TiN.

\subsubsection{Titanium diboride}

Titanium diboride can be formed using $\mathrm{TiCl}_{4}, \mathrm{BBr}_{3}$, and $\mathrm{H}_{2}$ [30]. Similar to the discussion for the synthesis of $\mathrm{TiC}$ the growth rate characteristics in the pore are determined by the mass transport of the titanium and boron species in the gas phase. It is assumed that the concentrations of the adsorbing titanium and boron species are equal to the input concentrations of $\mathrm{TiCl}_{4}$ and $\mathrm{BBr}_{3}$. The ratio of the growth rate constant over the adsorption constant for $\mathrm{TiBr}_{4}$ of the growth rate expression in Table 1 at a high surface coverage of $\mathrm{TiBr}_{4}$ is derived from CVD experiments [29]. There are no data available on the adsorption constant of $\mathrm{TiBr}_{4}$ on $\mathrm{TiB}_{2}$. Therefore, it is assumed that this adsorption constant is of the same order of magnitude as the adsorption constant of $\mathrm{TiCl}_{3}$ on $\mathrm{TiN}$.

Typical model parameters used in the model predictions for the deposition of $\mathrm{TiN}, \mathrm{TiC}$, and $\mathrm{TiB}_{2}$ in porous systems are given in Table III.

\section{Results and discussion}

The results of the synthesis of TiN in small tubes as reported by Van den Brekel et al. [41] can be used to validate the model. They observed a strong decrease in reaction rate as a function of the position in the reactor. This is an indication that there is a considerable depletion of reactant in the reactor, and that the apparent reaction order for the growth rate with respect to the $\mathrm{TiCl}_{4}$ input concentration is positive [27]. The relative decrease in deposition thickness with respect to the deposition thickness at the entrance of 
TABLE III Typical parameters used for the modelling of the ICVI process for TiN, TiC, and $\mathrm{TiB}_{2}$.

\begin{tabular}{lllll}
\hline Parameter & TiN & TiC & TiB $_{2}$ & \\
\hline$r_{\mathrm{i}}$ & $0.1-5000$ & $350-1500$ & 2.5 & $\mu \mathrm{m}$ \\
$L / r_{\mathrm{i}}$ & $10-10000$ & 80,342 & 1200 & - \\
$\tau$ & 1,4 & 1 & 4 & - \\
$P$ & $0.09-1$ & 0.09 & $0.1-1$ & $10^{5} \mathrm{~Pa}$ \\
$T$ & $1000-1273$ & 1373 & $823-1073$ & $\mathrm{~K}$ \\
$R(x=0)$ & $0.1-10$ & 5 & $2.4-4.8$ & $10^{-5} \mathrm{~mole} \mathrm{~m}^{-2} \mathrm{~s}^{-1}$ \\
\hline
\end{tabular}

the pore as a function of axial distance in the pore was measured. The experimental results and the model solutions are presented in Fig. 2. The model predictions are in agreement with the experiments. The decrease in the slope of the deposition profile near the middle of the pore is a consequence of the symmetry plane in the middle of the cylinder. Furthermore, the shape of the deposition profile is independent of the reactant concentration. This can be illustrated by the Thiele modulus for a first order reaction.

$$
\varphi=\frac{L}{2}\left(\frac{k}{2 r^{0} D_{\mathrm{e}}\left(\frac{L}{2}, 0\right)}\right)^{\frac{1}{2}}
$$

This Thiele modulus which is a measure for the deposition profile [41] is independent of the concentration. The presented deposition profile is independent of time as well provided that the thickness of the deposit is small with respect to the pore radius.

Any other shape of the deposition profile as a function of the axial distance relative to the thickness at the entrance of the pore can never be explained by first order kinetics. This can be illustrated by the deposition profiles for TiC in small tubes as reported by Van den Brekel et al. [41]. Under certain experimental conditions they found near the pore entrance an increase in the slope of the deposition profile for $\mathrm{TiC}$ into the pore. Such a deposition profile is typical for an adsorption-reaction mechanism [39]. Predicted $\mathrm{TiC}$ deposition profiles assuming first order reaction kinetics or a growth rate mechanism according to Equation 10 along with the experimental results are presented in Fig. 3. The numerical results are in reasonable agreement with the experimental data. However, some remarks have to be made concerning these presented numerical solutions of the model. Accurate growth rate constants for the deposition of TiC could not be derived from the growth rate data on dense substrates as reported by Stjernberg et al. [28], and Van den Brekel et al. [41], because the degree of depletion of the reactants in their reactors is unknown. Consequently, the derived reaction rate constant, given the assumption that the reactant concentration near the substrate is equal to the input concentration, will result in a reaction rate constant which is too low. Moreover, the deposition profile in the pore is not independent of the reactant concentration as discussed for a first order reaction rate dependence. However, the presented deposition profiles could be obtained by assuming that the $\mathrm{TiCl}_{4}$ concentration was 60 per cent of the input concentration. From this

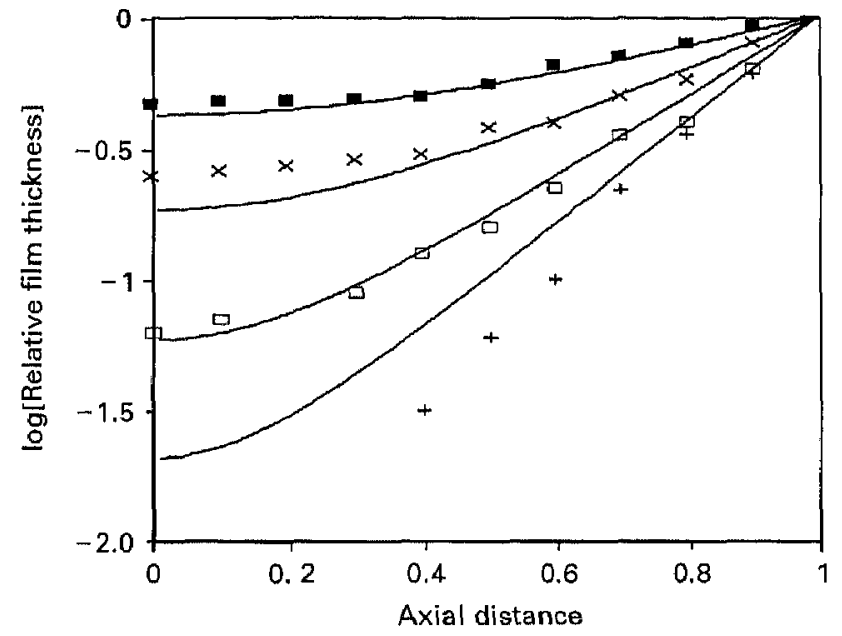

Figure 2 Deposition profiles of TiN in small tubes with different radii. The experimental points represent the relative thickness at different axial distances from the middle of the tube [41]. The solid lines are the predicted profiles fitted to the data points represented by (四) $r=1.4 \mathrm{~mm},(x) r=0.55 \mathrm{~mm},(\square) r=0.25 \mathrm{~mm}$ and $(+)$ $r=0.15 \mathrm{~mm}$. The pore length is $0.02 \mathrm{~m}$, the reaction temperature is $1123 \mathrm{~K}$, and the reactor pressure is $9 \times 10^{4} \mathrm{~Pa}$.

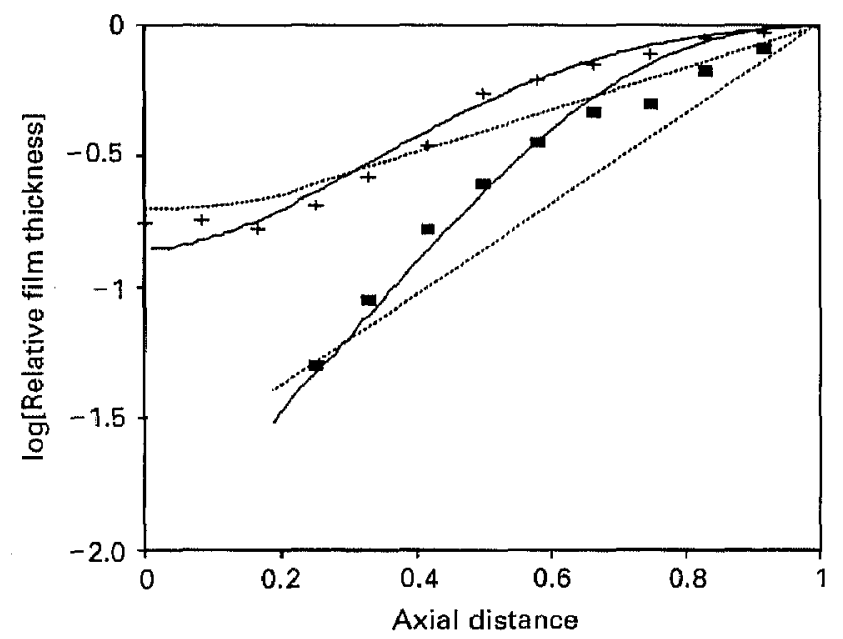

Figure 3 Deposition profiles of $\mathrm{TiC}$ in small tubes with different radii. The experimental points represented by the symbols, $(+)$ for $r=1.5 \mathrm{~mm}$ and $(\mathbf{\square})$ for $r=0.35 \mathrm{~mm}$ represent the relative thickness at different axial distances from the middle of the tubc [41]. The solid lines are the predicted profiles using equation (10) and the dashed lines represent the predicted profiles assuming first order reaction kinctics. The pore length is $0.12 \mathrm{~m}$, the reaction temperature is $1373 \mathrm{~K}$, and the reactor pressure is $9 \times 10^{3} \mathrm{~Pa}$.

discussion it is clear that these presented profiles can only be used for a qualitative comparison between the model results and experiments. It can be concluded that the results of a mathematical model can only be in 
agreement with the experimental results if an accurate growth rate expression is implemented in such a model.

Hitherto, the model simulations were applied for straight cylindrical pores. Often, such a simplified model is justified, and any complexity in the mass transfer in the pore network can be approximated by the calculation of an effective diffusion coefficient $[15,39,45,52]$. The correction factor $F$ for the effective diffusion coefficient in Equation 6 is dependent on the complexity of the pore network. We have assumed that $F$ is equal to four, i.e. a common value for the tortuosity factor for sintered porous ceramics. Furthermore, it is assumed that $F$ remains constant during the densification process. To evaluate the implications of a complex network on the densification the volumes of infiltrated $\mathrm{TiN}$ and $\mathrm{TiB}_{2}$ in the sintered porous alumina samples can be compared with the results of the model. The amount of mass deposited in the pore network can be obtained if it is assumed that the total mass increase during the ICVI process equals the sum of the mass increase at the geometrical outer surface of the substrate and the mass increase in the pore network [15]. Now, the volume increase of the deposit in the porous substrate relative to the initial pore volume can be determined using,

$$
X=\frac{m_{\mathrm{t}}-(1-\varepsilon) S M_{\mathrm{s}} R t}{\varepsilon \rho V}
$$

where $m_{\mathrm{t}}$ is the measured mass increase, $\varepsilon$ the initial porosity, $S$ the geometrical surface area, and $V$ the volume of the porous preform. The calculated versus the measured $\mathrm{TiN}$ and $\mathrm{TiB}_{2}$ volumes in the porous preforms are presented in Figs 4 and 5 in which the solid lines represent a perfect agreement between model and experiment. There is only a qualitative agreement between the measured and predicted values, because there is an overprediction in the results with respect to the infiltrated mass. This can be explained by one of the following cases.

(1) The constants in the kinetic expression used in the model are not accurate. This is a plausible argument for the results on $\mathrm{TiB}_{2}$, because the growth rate constants derived for the grow th rate expression are probably too low based on a similar discussion for the determination of the growth rate constant for TiC. These growth rate constants along with a reactant concentration which is too high will result in an overprediction of the mass deposited at a given process time.

(2) The kinetic expression as derived from experiments on precoated substrates or on metal substrates is not applicable for the growth rate in the CVI preform. For example, it is very well possible that the nucleation of the solid on the insulator $\mathrm{Al}_{2} \mathrm{O}_{3}$ is far more difficult than on metal surfaces. This would suggest that for relatively large amount of deposits the predicted volume should be closer to the measured volume of deposit. The results as presented in Figs 4 and 5 suggest that this might be one of the explanations.

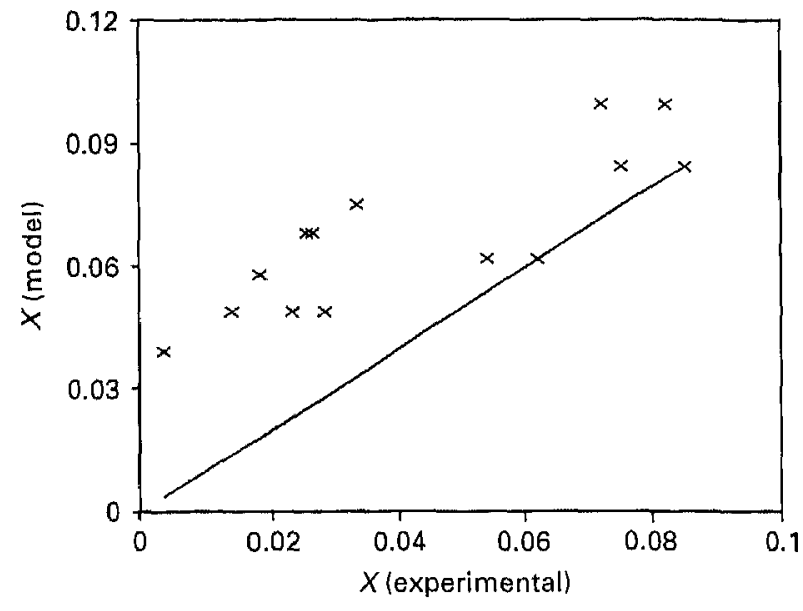

Figure 4 Predicted relative pore volume decrease versus the experimental relative pore volume decrease of $\mathrm{TiN}$ in porous sintered alumina. Solid line represents perfect agreement between experiment and model.

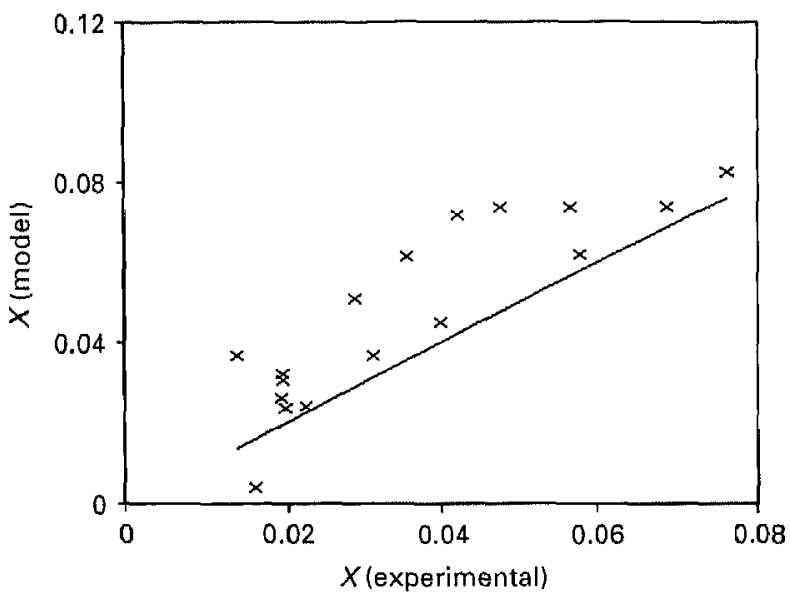

Figure 5 Predicted relative pore volume decrease versus the experimental relative pore volume decrease of $\mathrm{TiB}_{2}$ in porous sintered alumina. Solid line represents perfect agreement between experiment and model.

(3) Equation 25 is not valid. This equation is based on a simplified structure of the surface which is assumed to be flat with holes where the fraction of the surface area covered by holes should be equal to the porosity. (4) The additional resistance in the mass transport as a consequence of the complexity of the pore network cannot be compensated by the introduction of the tortuosity factor. For example, if the shape of the pores is similar to ink-bottles, then the mass transport is determined by the pore neck radius, and not by the average pore size, which is used in the model. In principle, additional complexilies or change in the characteristics of the pore network besides the tortuosity can be incorporated in the correction factor $F$ in Equation 6. For example, Wakao and Smith [63] have taken into account the fluctuation in porosity. However, this is only valid for samples where the porosity is isotropic. To our knowledge there are no reports on the change of the mass transfer resistance with increasing densification in non-isotropic porous preforms.

It is likely that a combination of the explanations given above is responsible for the mismatch. A model 
using the percolation theory would be more appropriate for these kind of samples. The results are expected to be less sensitive for the CVI process in fibre preforms using long process times, because the tortuosity is generally lower, the initial average pore size is larger, and the initial nucleation has a smaller effect on the final result.

\subsection{Thiele modulus}

The Thiele modulus at the initial stage of the process can be used to obtain conditions for an optimal densification $[37,38]$. However, the evolution of the pore geometry and the final densification might be different for Thiele moduli of the same value, because the evolution of the Thiele modulus during the densification process is dependent on a complex relationship of the process parameters. Thus, a series of model calculations have to be executed, which cover the whole range of variables present in the Thiele modulus for a given CVI process. Consequently, the results of the calculations have to be evaluated as a function of the Thiele modulus. Then, one might conclude that conditions for an optimal densification can be based on these calculations. The Thiele modulus might be used also for the evaluation of a CVI process, in which the process parameters are varied during the process [53]. In this case, the process parameters are changed during the process in such a way that the densification can be improved $[13,53]$. It is obvious that mathematical modelling is vital for the optimization of such a dynamic CVI process.

The final residual porosity as a function of a Thiele modulus for the adsorption-reaction mechanism with the formation of TiN will be discussed. This Thiele modulus for the formation of TiN can be obtained given the assumption that the $\mathrm{HCl}$ concentration is determined by the thermodynamic gas phase equilibrium. After substitution of Equation 9 into Equation 17, the Thiele modulus for the deposition of TiN in a porous preform can be obtained by integration of equation 17

$$
\begin{gathered}
\varphi=\frac{L}{2}\left(\frac{k C_{N_{2}}^{1 / 2} C_{\mathrm{H}_{2}}^{1 / 2}}{4 r^{0} D_{\mathrm{e}}\left(\frac{L}{2}, 0\right)}\right)^{\frac{1}{2}} C_{\mathrm{TiCl}_{3}}\left(s^{\mathrm{l}}\right)^{2} s^{\mathrm{n}} \\
\times\left[\frac{s^{1}-1}{U|U-W|}+\frac{\ln \left(s^{\mathrm{l}} / s^{\mathrm{n}}\right)}{(U-W)^{2}}\right]^{-\frac{1}{2}} \\
s^{\mathrm{t}}=\frac{1}{\left(1+U C_{\mathrm{HCl}}\right)} \\
s^{\mathrm{n}}=\frac{1}{\left(1+W C_{\mathrm{TiCl}_{3}}\right)}
\end{gathered}
$$

where $U$ is $K_{\mathrm{HCl}} /\left(K_{\mathrm{H}_{2}} C_{\mathrm{H}_{2}}\right)^{1 / 2}, W$ is $K_{\mathrm{TiCl}_{3}}$. Here $s^{\mathrm{l}}$ and $s^{n}$ are the free titanium and nitrogen sites at the surface of the TiN layer, respectively. The asymptotic value at low concentration of this Thiele modulus is similar to Equation 24, because at a low concentration the apparent reaction order behaviour for growth rate Equation 9 is one. The residual porosity as a function of the initial Thiele modulus for the formation of TiN is presented in Fig. 6. Apparently, this initial Thiele

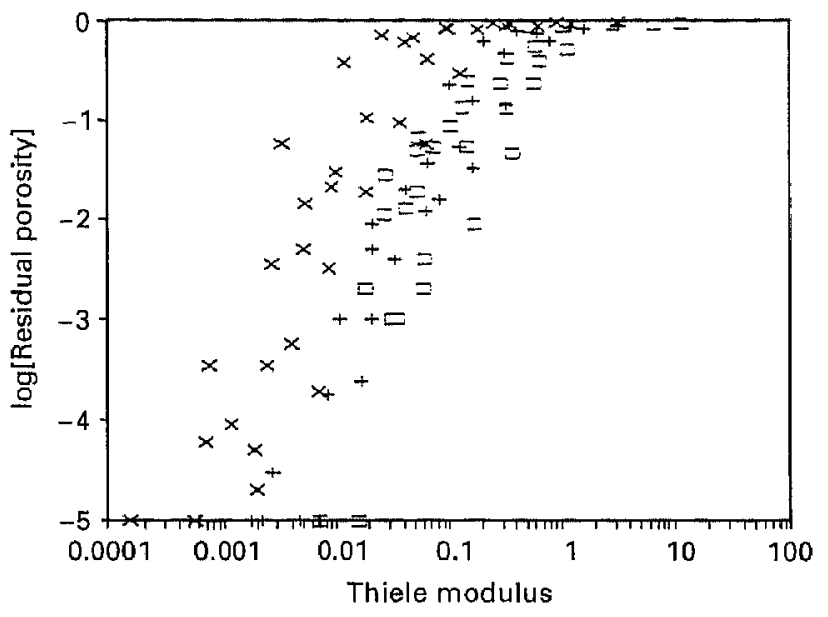

Figure 6 Predicted residual porosity versus the calculated Thicic modulus for the synthesis of TiN. The experimental conditions summarized in Table III are used for the calculations. The data were taken at; $(x) 1000 \mathrm{~K},(+) 1123 \mathrm{~K}$ and $(\square) 1273 \mathrm{~K}$.

modulus for a complex reaction kinetics, in contrast to a Thiele modulus for a first order reaction kinetics, cannot account for differences in densification at different temperatures. A better densification with increasing temperature is obtained at equal Thiele moduli. This implies that at higher reaction temperatures the decrease in mass deposit in the pore is less sensitive to the increase in mass transfer resistance during the CVI process. This is a consequence of the decrease of the adsorption constants which leads to an increase in the growth rate with increasing temperature. To illustrate this phenomenon a simple hypothetical adsorption-reaction mechanism will be used. The reaction rate according to a one-component dissociative adsorption-reaction mechanism can be expressed as in Equation 29 [39].

$$
R \propto \frac{C_{\mathrm{A}}}{\left(1+K_{\mathrm{A}} C_{\mathrm{A}}\right)^{2}}
$$

The growth rate as a function of the concentration at three arbitrary temperatures is presented in Fig. 7. With increasing temperature equal growth rates can only be found with increasing reactant concentrations. Consequently, at a given process time the growth rate is less sensitive to a depletion of reactants in the pore at high temperatures than at low temperatures. This will result in a better densification of the preform at higher temperatures at equal Thiele moduli provided that the growth rate at the pore entrance is kept constant.

This Thiele modulus cannot unambiguously predict the densification characteristics. It can be used only to predict some trends in the densification of porous preforms. Some of these generalized conditions can be a good guidance for an optimum densification of the preform. In general, concordant to the calculations for deposition of TiN in a pore, it is likely that a residual porosity of less than one per cent will be obtained if the initial Thiele modulus is smaller than $5 \times 10^{-4}$. This condition is thought to be valid also for any other adsorption-reaction mechanism [39]. However, a CVI process with such a small Thiele modulus will 


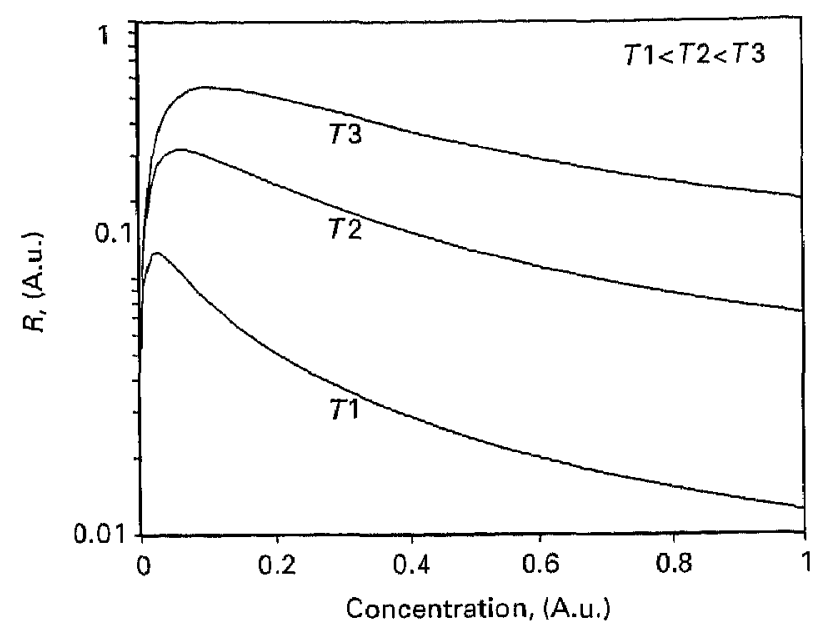

Figure 7 Growth rate of an hypothetical adsorption-reaction mechanism as a function of reactant concentration at three different temperatures.

not be practical, because of the unacceptably long process times before the final density is obtained. Therefore, more precise conditions at higher Thiele moduli should be given.

\subsection{Conditions for optimal densification}

The CVI process for deposition of carbides, nitride, and borides in porous preforms as listed in Table 1 are evaluated, and some generalized conditions for an optimal densification using acceptable process times will be given. The formation of TiN and $\mathrm{TiC}$ are used to illustrate the given conditions:

\subsubsection{Reactant concentration}

Most of the binary compounds can be formed using a limited range of reactant ratios. The formation of a single binary phase is determined by thermodynamics and surface kinetics. Themodynamic equilibrium calculations can be used to predict the stability regions for the single phase binary compounds as a function of the gas phase composition in the CVD process. The use of these so-called CVD diagrams is of course limited, because the thermodynamically stable phase is not necessarily the observed phase after a CVD experiment. However, this is a well known and useful method to predict beforehand whether a single phase deposition, or a codeposition will be obtained in the CVD experiments [64].

For example, with an excess of $\mathrm{CH}_{4}$ with respect to $\mathrm{TiCl}_{4}$ under certain experimental conditions a codeposition of carbon and $\mathrm{TiC}$ can be found, and a single phase of $\mathrm{TiC}$ will be observed with an excess of $\mathrm{TiCl}_{4}$ with respect to $\mathrm{CH}_{4}$ in the gas phase [65]. Thus, the presence of a large ratio of $\mathrm{TiCl}_{4}$ over $\mathrm{CH}_{4}$ in the gas phase will result in the deposition of $\mathrm{TiC}$ in a pore, provided that this condition of an excess of $\mathrm{TiCl}_{4}$ with respect to $\mathrm{CH}_{4}$ remains valid throughout the pore. This is difficult to predict a priori, because the diffusivity of $\mathrm{TiCl}_{4}$ is less than that of $\mathrm{CH}_{4}$. In general, a reactant ratio should be chosen which might result in a single phase deposit throughout the pore, and CVD diagrams can be used to verify as to whether a change in the reactant ratio into the pore will result in an undesirable codeposition. An advantage of a high concentration of the titanium species is the presence of a negative apparent order with respect to the titanium species concentration in the growth rate expression for the formation of $\mathrm{TiC}$. Thus, an increase in the $\mathrm{TiCl}_{4}$ concentration will result in a concomitant decrease in the growth rate at the pore entrance which will favour the densification as revealed by the calculations. The concentration of $\mathrm{TiCl}_{4}$ can not be increased without limitations, because an increase in the $\mathrm{TiCl}_{4}$ concentration will result in a decrease in the growth rate of $\mathrm{TiC}$ at the pore entrance which in turn might result in unacceptably long process times before pore plugging.

This is in contrast to a CVI process in which the residual porosity is independent of the reactant concentration. This is observed for a reaction mechanism with an apparent first order reaction mechanism with respect to a species $A$, and for which Equation 18 is valid, for example the deposition of TiN at a low $\mathrm{TiCl}_{4}$ concentration. Moreover, the process time is decreased with increasing concentration. Thus, the concentration should be selected as high as possible when the growth rate has an apparent first order dependence. At low reactant concentrations the reaction mechanisms for the growth rate of binary compounds have a positive order with respect to the reactants. Often, Equation 18 is not valid for the deposition of binary compounds in porous preforms. Consequently, the densification is not independent of the reactant concentrations any more. Model calculations reveal that for the deposition for $\mathrm{BP}, \mathrm{Si}_{3} \mathrm{~N}_{4}$, and $\mathrm{SiC}$ the residual porosity increases with increasing concentration as long as the denominator in the growth rate expression is one. Thus, the reactant concentrations should be chosen as low as possible if the growth rate has a positive order dependence $(\geqslant 1)$ with respect to more than one reactant concentration.

\subsubsection{Reactor pressure}

The reactor pressure dependence on the densification in the CVI process is complicated, because the pressure has a strong influence on the mass transfer in the gas phase as well as on the growth rate. In principle, model calculations should be performed for each specific process in order to be able to optimize the densification by tailoring the reactor pressure. However, some trends about the influence of the reactor pressure on the densification can be given. Il will be assumed that the influence of a change in the reactor pressure on the CVI process is considered at a constant feed rate of reactant, and that the ratio of these reactants in the gas phase does not change with a change in the reactor pressure. This latter assumption is not necessarily valid if the gas phase is quasiequilibrated, because there can be a shift in the equilibrium concentrations with a change in the reactor pressure. The reactor pressure influence on the growth 
rate for the deposition of several binary compounds is given in Table IV.

If the denominator equals one in the growth rate expression then the apparent reaction order with respect to the reactor pressure is constant throughout the pore, and a lower reactor pressure will favour the densification. The apparent reaction order with respect to the reactor pressure for a typical adsorption-reaction mechanism will have a complex dependence on the reactor pressure as illustrated by the two extreme cases for the reaction rate expressions 9-16 in Table IV. The model calculations suggest that a better densification is obtained for most of the simulations with a decrease in pressure if the apparent order for the growth rate expression with respect to the reactor pressure is $\geqslant 0$, and that an increase in pressure might favour the densification if the apparent order for the growth rate expression with respect to the pressure is $<0$. However, model calculations should be performed in order to be able to study to what extent the residual porosity is changed with a change in the reactor pressure.

If the mass transport in the gas phase is determined by Knudsen diffusion then the change in the residual porosity with a change in the reactor pressure is the same as for a change in the reactant concentrations using a constant reactant ratio, because Knudsen diffusion is independent on the reactor pressure.

\subsubsection{Reaction temperature}

The choice of reaction temperature is limited, because the deposition of a single phase is often found within a relatively small temperature range. Similar to the discussion for the concentration, thermodynamic equilibrium calculations can be used to evaluate the selection of the reaction temperature. Moreover, the temperature region in which the reaction rate expression is valid is often smaller than one might conclude from the CVD-diagrams. In general, the growth rate exhibits a strong dependence on the temperature, whereas the mass transfer in the gas phase has a small dependence on the temperature. Thus, a change in the infiltration characteristics is primarily determined by a change in the growth rate expression.

If the growth rate is determined by an adsorptionreaction mechanism then the reaction temperature in combination with the concentration which is present in the denominator in the growth rate expression, should be selected as high as possible as discussed above for the Thiele modulus of TiN. However, numerical model calculations should be executed in order to determine the optimum conditions for the CVI process if the temperature dependence of the growth rate constant in the numerator is stronger than the temperature dependence of the adsorption constants in the denominator. The smallest residual porosity is found at the lowest reaction temperature if there is an apparent positive order for the growth rate. This is the

TABLE IV The apparent overall order for the growth rate with respect to the reactor pressure for two extreme cases

\begin{tabular}{|c|c|c|c|c|c|c|c|c|}
\hline \multirow{2}{*}{$\begin{array}{l}\text { Solid: } \\
\text { Equation: }\end{array}$} & \multirow{2}{*}{$\begin{array}{l}\text { TiN } \\
9\end{array}$} & \multirow{2}{*}{$\begin{array}{l}\mathrm{TiC} \\
10\end{array}$} & \multirow{2}{*}{$\begin{array}{l}\mathrm{TiB}_{2} \\
11\end{array}$} & \multirow{2}{*}{$\begin{array}{l}B P \\
12\end{array}$} & \multicolumn{2}{|c|}{$\mathrm{B}_{x} \mathrm{C}_{y}$} & \multirow{2}{*}{$\begin{array}{l}\mathrm{Si}_{3} \mathrm{~N}_{4} \\
15\end{array}$} & \multirow{2}{*}{$\begin{array}{l}\mathrm{SiC} \\
16\end{array}$} \\
\hline & & & & & 13 & 14 & & \\
\hline Denominator $\simeq 1$ : & 2 & $5 / 2$ & 2 & 2 & 1 & $1 / 2$ & 2 & 2 \\
\hline Denominator $\gg 1$ : & 0 & $1 / 2$ & 0 & 0 & 0 & $-1 / 2$ & 1 & 1 \\
\hline
\end{tabular}

TABLE V The influence of the process parameters on the residual porosity and process time for the ICVI process

\begin{tabular}{|c|c|c|c|c|c|c|c|}
\hline \multicolumn{2}{|l|}{ Growth rate expression } & \multicolumn{6}{|c|}{ Decrease in: } \\
\hline \multirow{2}{*}{$\begin{array}{l}\text { concentration } \\
\text { dependence }\end{array}$} & & \multicolumn{2}{|l|}{$C_{\mathrm{A}}$} & \multicolumn{2}{|l|}{ Pressure } & \multicolumn{2}{|c|}{ Temperature } \\
\hline & & $\begin{array}{l}\text { Residual } \\
\text { porosity }\end{array}$ & $\begin{array}{l}\text { Process } \\
\text { tine }\end{array}$ & $\begin{array}{l}\text { Residual } \\
\text { porosity }\end{array}$ & $\begin{array}{l}\text { Process } \\
\text { time }\end{array}$ & $\begin{array}{l}\text { Residual } \\
\text { porosity }\end{array}$ & $\begin{array}{l}\text { Process } \\
\text { time }\end{array}$ \\
\hline \multirow[t]{4}{*}{$C_{A}^{\mathrm{a}} C_{\mathrm{1b}}^{\mathrm{b}}$} & $0<a<1, b>0, C_{\mathrm{B}} \geqslant C_{\mathrm{A}}$ & - & - & + & - & + & - \\
\hline & $a=b=1 / 2, C_{\mathrm{B}}=C_{\mathrm{A}}$ & $x$ & - & + & - & + & - \\
\hline & $a=1, b>0, C_{\mathrm{B}} \geqslant C_{\mathrm{A}}$ & $x$ & - & + & - & + & - \\
\hline & $a>1, b>0, C_{\mathrm{A}} \approx C_{\mathrm{B}}$ & + & - & + & - & + & - \\
\hline$C_{\mathrm{A}}^{\mathrm{a}} C_{\mathrm{B}}^{\mathrm{b}+}$ & $c<a+b, K_{\mathrm{A}} C_{\mathrm{A}} \gg 1$ & - & $+1-$ & $0 /+$ & - & $-*$ & - \\
\hline \multirow[t]{3}{*}{$\overline{\left(1+K_{A} C_{\mathrm{A}}+K_{\mathrm{B}} C_{\mathrm{B}}\right)^{\mathrm{t}}}$} & & & & & & & \\
\hline & $c=a+b, K_{A} C_{\mathrm{A}} \gg 1$ & - & + & $0 /+$ & $\mathrm{x}$ & $-^{*}$ & - \\
\hline & $c>a+b, K_{A} C_{A} \geqslant 1$ & - & + & $0 /-$ & + & $-*$ & - \\
\hline
\end{tabular}

+ : Beneficial for residual porosity or process time.

- : Detrimental for residual porosity or process time.

$\mathrm{x}$ : No influence on residual porosity.

0: In some cases influence cannot be predicted a priori, model calculations should be performed.

t: or a similar growth rate expression as listed in Table I.

*: at constant process time. 
reverse with respect to the condition for the reaction temperature for a typical adsorption-reaction mechanism at high concentrations. The influence of the process parameters on the densification for the ICVI process is summarized in Table $\mathrm{V}$.

Table V can be used as a guideline for the determination of the optimum of the process parameters for the ICVI process. From this information it can be concluded that knowledge of the kinetics of the CVD growth is very important for the CVI process. Similar strong dependencies on the differences in kinetic behaviour can be expected for non-isothermal and non-isobaric processes.

\section{Conclusions}

The numerical solutions of a mathematical description of a CVD process in an open cylinder under isothermal and isobaric conditions are used to evaluate the influence on the infiltration characteristics of different kinetic expressions for the formation of several binary compounds. Experimental results on the deposition of $\mathrm{TiN}$ and $\mathrm{TiC}$ in small tubes are used to validate the importance of the different kinetic expressions for the infiltration characteristics. The deposition profiles as predicted by the model calculations are in agreement with the experimentally determined deposition profiles of $\mathrm{TiN}$ and $\mathrm{TiC}$ in small tubes. Moreover, it can be concluded that the shape of the deposition profiles is determined by the heterogeneous reaction kinetics. There is only a qualitative agreement between the predicted densification and measured densification for the synthesis of $\mathrm{TiN}$ and $\mathrm{TiB}_{2}$ in sintered porous alumina.

If the growth rate in the pore is limited by the mass transfer of a single species then a Thiele modulus can be calculated to evaluate the ICVI process. In principle, this Thiele modulus is only valid for the initial stages of the process, because it cannot predict the influence of the changing pore geometry on the densification. Model calculations reveal that there is a scattering for the predicted residual porosity as a function of the Thiele modulus for TiN. Moreover, it cannot fully account for the changes in densification at different temperatures. Given these uncertainties it is likely that a residual porosity of less than one per cent will be obtained if the Thiele modulus is smaller than $5 \times 10^{-4}$. A decrease in these parameters will increase the process time provided that for the growth rate the reaction order in the reactant concentration is positive. A decrease in the parameters will result in a decrease in the residual porosity if for the apparent reaction order in the reactant concentration the condition $\geqslant 1$ holds, whereas an increase in residual porosity is found if the overall apparent order in the reactor pressure is negative.

\section{References}

1. H. O. PIERSON, Handbook of Chemical Vapour Deposition (CVD), (Noyes Publications, 1992) 225.

2. F. CHRISTIN, R. NASLAIN and C. BERNARD, in Proceedings of the 7 th International Conference on Chemical Vapour
Deposition, 1979, edited by T. O. Sedgwick and H. Lydtin (The Electrochemical Society, Princeton, 1979) 79-3 499.

3. R. COLMET, I. LHERMITTE-SEBIRE and R. NASLAIN, Adv, Ceram. Mater., 1 (1986) 185.

4. S. MARINKOVIĆ and S. DIMITRIJEVIĆ, J. Chimie Physique 84 (1987) 1421.

5. D. P. STINTON, T. M. BESMANN and R. A. LOWDEN, Ceram. Bull. 67 (1988) 350.

6. T. M. BESMANN, R. A. LOWDEN, B, W. SHELDON and D. P. STINTON, in Procedings of the 11 th International Conference on Chemical Vapour Deposition, Seattle, USA, 1990, edited by K. E. Spear and G. W. Cullen, (The Electrochemical Society, Pennington, 1990) 90-12 482.

7. E. FITZER and R. GADOW, Amer Ceram. Soc. Bull. 65 (1986) 326.

8. R. E. FISCHER, C. V. BUCKLAND and W. E. BUSTAM ANTE, Ceram. Eng. Sci. Proc. 6 (1985) 806.

9. J. Y, ROSSIGNOL, J. M. QUENISSET and R. NASLAIN, Composites 18 (1987) 135.

10. P. REAGAN, M. F. ROSS and F. N. HUFFMAN, Adv. Ceran. Mater. 3 (1988) 198.

11. R. D. VELTRI, D. A. CONDIT and F. S. GALASSO, J. Amer. Ceram. Soc. 72 (1989) 478.

12. E. FITZER, W. REMMELE and G. SCHOCH, Jounal de Physique (Colloque C5, suppl. au Journal de Physique II, 1989) C5-209.

13. K. SUGIYAMA and Y. OHSAWA, J. Mat. Sci. 7 (1988) 1221.

14. D. J. DEVLIN, R. S. BARBERO and R. P. CURRIER, in Proceedings of the 11th International Conference on Chemical Vapour Deposition, Seattle, USA, 1990, edited by K. E. Spear and G. W. Cullen (The Electrochemical Society, Pennington, 1990) 90-12 499.

15. J. Y. ROSSIGNOL, F. LANGLAIS and R. NASLAIN in Proceedings of the 9th International Conference on Chemical Vapour Deposition, Seatle, USA, 1984, edited by McRobinson, (The Electrochemical Society, Pennington, 1984) 84-7 596.

16. A. J. CAPUTO and W. J. LACKEY, Ceram. Eng. Sci. Proc. 5 (1984) 654.

17. T. L. STARR, ibid. 8 (1987) 951.

18. T. D. GULDEN, J. L. KAAE and K. P. NORTON in Proceedings of the 11 th International Conference on Chemical Vapour Deposition, Seattle, USA, 1990, edited by K. E. Spear and $G$. W. Cullen (The Electrochemical Society, Pennington, 1990) 90-12 546.

19. J. I. MORELL, D. J. ECONOMOU and N. R. AMUNDSON, J. Electrochem. Soc. 139 (1992) 328.

20. E. FITZER, Joumal de Physique IV (Colloque C2, suppl. au Journal de Physique II, 1991) C2-509.

21. Y. S. LIN and A. F. BURGGRAAF, Chem. Eng. Sci. 46 (1991) 3067 .

22. M. SHIROYAMA, JP No. 61-207282, (1986).

23. J. P. DEKKER, P. J. van der PUT, H. J. VERINGA and J. SCHOONMAN, AUSTCERAM 92, Proceedings International Ceramics Conference edited by M. J. Bannister (CSIRO Australia, 1992) 2712.

24. M. IIZAKA and H. KOMIYAMA, Procecdings of the 11 th International Conference on Chemical Vapour Deposition, Seattle, USA, 1990, edited by K. E. Spear and G. W. Cullen, (The Electrochemical Society, Pennington, 1990) 90-12 596.

25. C. Z. RONG, D. Y. SHENG and M. H. FANG, Sulf. Eng. 5 (1989) 315.

26. N. NAKANISHI, S. MORI and E. KATO, J. Electrochem. Soc., 137 (1990) 322.

27. J. P. DEKKER, P. J. van der PUT, H. J. VERINGA and J. SCHOONMAN, J. Electrochem. Soc. 141 (1994) 787.

28. K.G. STJERNBERG, H. GLASS and E. HINTERMANN, Thin Solid Films 40 (1977) 81.

29. T. TAKA HASHI and H. KAMIYA, J. Cryst. Growth 26 (1974) 203.

30. J. P. DEKKER, P. J, van der PUT, H. J. VERINGA and J. SCHOONMAN, J. of C.V.D. 1 (1994) 317.

31. E. M. KELDER, A. GOOSSENS, P. J, van der PUT and J. SCHOONMAN, in Proceedings of the 1 th International Conference on Chemical Vapour Deposition, Scattle, USA. 
1990, edited by K. E. Spear and G. W. Cullen, (The Electrochemical Society, Pennington, 1990) 90-12 120.

32. L. VANDENBULCKE and G. VUILLARD, in Proceedings of the 8th International Conference on Chemical Vapour Deposition, 1981, edited by J. M. Blocher Jr. and G. E. Vuillard (The Electrochemical Society, Pennington, 1981) 81-7 95.

33. K. S. YI and J. S. CHUN, in Proceedings of the JOth International Conference on Chemical Vapour Deposition, 1989, edited by G. W. Cullen and J. M. Blocher Jr., (The Electrochemical Society, Pennington, 1987) 87-7 57.

34. K. F. ROENIGK and K. F. JENSEN, J. Electrochem. Soc. 134 (1987) 1777.

35. F. LANGLAIS and C. PREBENDE, in Procecdings of the 11th International Conference on Chemical Vapour Deposition edited by K. E. Spear and G. W. Cullen, (The Electrochemical Society, Pennington, 1990) 90-12 686.

36. T, E. WILKE, K. A. TURNER and C. G. TOUKADIS, Chem Eng. Sci. 41 (1986) 643.

37. S. MIDDLEMANN, J. Mater. Res. 4 (1989) 1515.

38. B. W. SHELDON, ibid. 5 (1990) 2729

39. R. MOENE, J. P. DEKKER, M. MAKKEE, J. SCHOONMAN and J. A. MOULIJN, J. Electrochem. Soc. 141 (1994) 282.

40. R. NASLAIN, F. LANGLAis and R. FEDOU, in Proceedings of the 7 th European Conference on Chemical Vapour Deposition, Perpignan, France, 1989, edited by M. Ducarroir, C. Bernard and L. Vandenbulcke (Editions de Physique, Les Ulis, 1989) C5-191.

41. C. H. J. van den BREKEL, R. M. M. FONVILLE, P. J. M. van der STRATEN and G. VERSPUl, in Proceedings of the 8th International Conference on Chemical Vapour Deposition edited by J. M. Blocher Jr. and G. E. Vuillard, (The Electrochemical Society, Pennington, 1981) 81-7 412

42. N. H. TAI and T, W. CHOU, Mat. Res. Soc. Symp. Proc. 120 (1988) 185 .

43. Idem. J. Amer. Ceram. Soc. 73 (1989) 414.

44. S. M. GUPTE and J. A. TSAMOPOULOS, J. Electrochem. Soc. 136 (1989) 555.

45. Y.S. LIN, in Proceedings of the 11 th International Conference on Chemical Vapour Deposition, Seattle, USA, 1990, edited by K. E. Spear and G. W. Cullen, (The Electrochemical Society, Pennington, 1990) 90-12 532.
46. R. FEDOU, F. LANGLAIS and R. NASLAIN, ibid. 90-12 513.

47. R. R. MELKOTE and K. F. JENSEN, ibid. 90-12 506.

48. Idem. AIChE Jotnnal 35 (1989) 1942.

49. N. H. TAI and T. W. CHOU, "Metals \& Ceramic Matrix Composites" edited by R. B. Bhagat, A. H. Clauer, R. Kumar and A. M. Ritter, (The Mincrals, Metals \& Materials Society, 1990) 303.

50. S. M. GUPTE and J. A. TSAMOPOULOS, J. Electrochem. Soc. $137(1990) 1626$.

51. Idem, ibid. 137 (1990) 3675.

52. G. Y. CHUNG, B. J. MCCOY, J. M. SMITH, D. E. CAGLiOSTRO and M. CARSWELl, Chem. Eng. Sci. 46 (1991) 723.

53. S.V. SOTIRCHOS, AIChE Joirnal 37 (1991) 1365.

54. R. P. CURRIER, J. Amer. Ceram. Soc. 73 (1990) 2274.

55. B. W. SHELDON and T. BESMANN, ibid. 74 (1991) 3046.

56. A. J. FORTINI and A. S. FAREED, in Proceedings of the 11 th International Conference on Chemical Vapour Deposition, Seattle, USA, 1990, edited by K. E. Spear and G. W. Cullen, (The Electrochemical Society, Pennington. 1990) 90-12 525.

57. K. B. BISCHOF F, Chem. Eng. Sci. 18 (1963) 711.

58. R. C. REID, J. M. PRAUSNITZ and B. E. POLING, "The Properties of Gases and Liquids" 4th Edn (McGraw-Hill, New York, 1987) Ch. 11.

59. R, B. BIRD, W. E. STEWARD and E. N. LIGHTFOOT, "Transport Phenomena" (Wiley, New York, 1960).

60. H. H. LEE, "Heterogeneous Reactor Design", (Buttersworth Publishers, Boston, 1985) 118.

61. K. B. BISCHOFF, A.I.Ch.E. Joumal 11 (1965) 351.

62. E. SADA and H, KUMAZAWA, Chem. Eng. Sci. 28 (1973) 1903.

63. N. WAKAO and J. M. SMITH, ibid. 17 (1962) 825

64. K. E. SPEAR and R, R. DIRKX, Pure and Appl. Chem. 62 (1990) 89

65. L., VANDENBULCKE, J. Electrochem. Soc. 128 (1981) 1584.

Received 14 April 1994

and accepted 1 December 1995 